\title{
The Influence of the Driving Speed and Vertical Acceleration of the Mobile Machine on the Change of Soil Packing
}

\author{
Mykola Artiomov $^{1}$, Dmytro Klets ${ }^{2 *}$, Volodymyr Boldovskyi ${ }^{3}$, Andrii Makovetskyi ${ }^{3}$, Kateryna Kostyk ${ }^{4}$ \\ ${ }^{I}$ Kharkiv Petro Vasylenko National Technical University of Agriculture \\ ${ }^{2}$ Kharkiv National Automobile and Highway University \\ ${ }^{3}$ National Aerospace University named after N. Zhukovsky «KhAI» \\ ${ }^{4}$ National Technical University «Kharkiv Polytechnic Institute» \\ *Corresponding author E-mail: d.m.klets@gmail.com
}

\begin{abstract}
The article deals with the processes of changing the vertical forces acting on the propulsion of mobile machines, causing soil compaction when changing the driving speed and vertical accelerations of a mobile machine moving on a deformable soil. The influence of parameters and characteristics of the running gear system of the wheeled tractor, as well as the traction load on the value of vertical accelerations when moving along the soil, is determined. The dependence of the influence of vertical accelerations on the dynamic loads on the axle of the tractor front and rear axles is determined. The dependence of the soil density variation caused by the action of dynamic loads from the propulsion of the tractor front and rear axles has been determined.
\end{abstract}

Keywords: Acceleration; Packing; Soil; Speed; Tractor.

\section{Introduction}

When rolling an elastic wheel on a deformable surface, the deformation of the soil occurs, resulting in the formation of a gauge, and deformation of the tire. Studies show that energy costs for overcoming hysteresis losses are considerably less than the cost of soil deformation. They make no more than $10-15 \%$ of the total energy consumed by rolling the elastic wheel on a deformable surface. Therefore, under considered conditions, the rolling resistance can be reduced mainly due to the deformation of the soil, i.e., the decrease of the depth of the gauge formed by the rolling wheels. This can be achieved by increasing the tire contact area, which requires reducing the air pressure in the tire. At the same time, the energy losses in the tire will increase, but the total rolling loss will still be less. Depending on the design features of the tractor chassis (the type and characteristics of the suspension, propellers, etc.), the degree of impact on the soil varies considerably. The propulsion parameters (the shape and dimensions of the groundwall, the air pressure in the propeller, etc.) have a significant effect on the soil compaction.

\section{Analysis of Publications and Studies}

Soil compaction is one of the most destructive effects of machine traffic. Compaction increases soil mechanical strength and reduces its porosity, plant rooting and ultimately the yield [1]. When calculating the magnitude of the impact caused by the wheel propeller on the ground, the main difficulty is the complex geometric shape of the wheel $[2,3]$. In the general case, the bearing surface of pneumatic wheels having the corresponding tread consists of protrusions and recesses of various configurations. In this case, the line of intersection of the radial plane passing through the axis of wheel rotation and the outer surface of the tire tread of the unloaded by external forces machine has a finite radius $[4,5]$. The above features greatly complicate the creation of calculated dependencies necessary to identify the distribution of the contact pressure of pneumatic tires on the wheel support, which is soil [6-8]. Two schemes, which are used for mathematical description [9-11] of the wheel interaction with a bearing surface, are known. In the first scheme they consider the fixed moment of a rolling wheel on the support surface. In this case, in all variants of the given scheme, it is common that the front and rear parts of the deformable wheel or the front and rear parts of the deformable bearing surface are not the same (an unsymmetrical diagram of contact pressures distribution, the length of the tire loading and unloading branches vary, a different level of the front and rear support surfaces [12]. In the second scheme they consider the compression of a cylindrical body with an initially cylindrical surface.

\section{Purpose and Objectives of the Study}

The purpose of the study is to develop a method for estimating the influence of the driving speed and vertical acceleration of the mobile machine on the change of soil packing in various driving regimes. To achieve this goal, it is necessary to solve the following tasks:

- to determine the influence of parameters and characteristics of the running gear system of the wheeled tractor on the value of vertical accelerations;

- to determine the dependence of the influence of vertical accelerations on the dynamic loads on the axle of the tractor front and rear axles;

- to determine the dependence of the soil density variation caused by the action of dynamic loads from the propulsion of the tractor front and rear axles. 


\section{Research Results}

One of the ways to reduce soil compaction is to reduce the specific pressure of propulsion to the soil. However, the problem of soil compaction cannot be solved only by reducing the specific pressure of tractor propulsion. The fact is that when conducting spring field work on the cultivation of grain crops (moisture closure, presowing cultivation, sowing, harrowing or sowing of crops), 50$60 \%$ of the field area are compacted by the driving machines of the tractor, and while cultivating common crops, more than $90 \%$ of the field area are compacted. Moreover, up to $30-40 \%$ of the field area is compacted twice, and up to $10-20 \%$ is compacted three times.

Table 1: Degree of tractor propulsion impact on the soil

\begin{tabular}{|c|c|c|c|}
\hline Tractor brand & Mass, kg & $\begin{array}{l}\text { Specific propul- } \\
\text { sion pressure, } \\
\mathrm{kg} / \mathrm{cm}^{2}\end{array}$ & $\begin{array}{l}\text { Single pass soil } \\
\text { compaction, } \\
\mathrm{g} / \mathrm{cm}^{3}\end{array}$ \\
\hline DT -75 & 7000 & 0.5 & 1.15 \\
\hline$T-4 A$ & 8300 & 0.5 & 1.2 \\
\hline MTZ - 80 & 3760 & 1.2 & 1.32 \\
\hline $\mathrm{T}-150 \mathrm{~K}-09$ & 8200 & $1.4-2.0$ & 1.35 \\
\hline $\mathrm{K}-701$ & 13500 & $1.5-2.5$ & 1.42 \\
\hline $\mathrm{K}-744 \mathrm{R} 2$ & 15700 & $1.6-2.6$ & 1.5 \\
\hline $\mathrm{K}-744 \mathrm{R} 3$ & $17500-20000$ & $1.7-2.7$ & 1.55 \\
\hline
\end{tabular}

The vertical dynamic impact of the wheel on the soil is complex, which is difficult to describe mathematically. To simplify the use of a mathematical device, the load impacts of the wheel propulsion on the soil can be represented as periodic (harmonic) that arise when moving on aligned fields.

When calculating the dynamic loads from the wheel to the soil, we assume that the loads are harmonic in nature $[13,14]$.

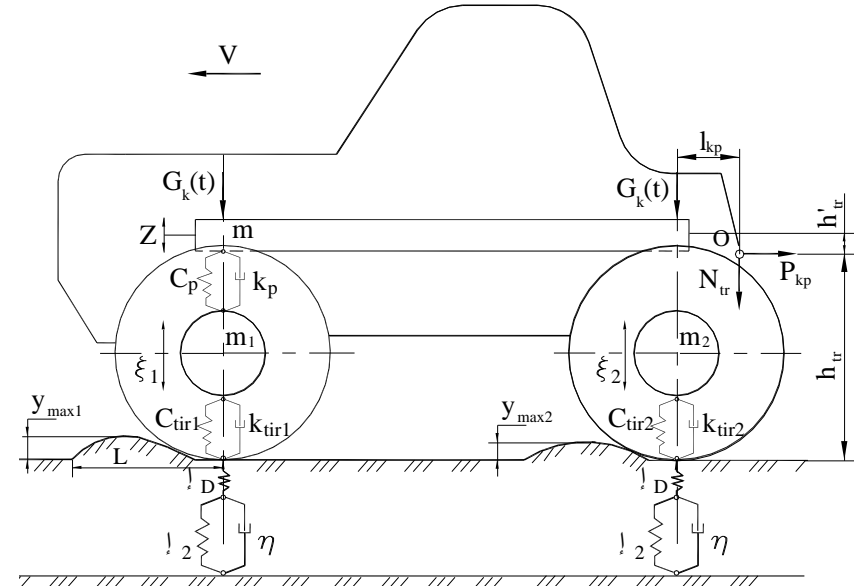

Fig. 1: Dynamic model of a wheeled tractor with vertical vibrations on a deformable support base

At the initial moment of tractor driving, the shock loads from the wheel to the soil appear due to the wheel falling from a certain height of the roughness, at the same time, at the initial moment of time $(t=0)$, the mechanical stresses increase by a jump from zero to the maximum of $\sigma_{m}$, and then changes according to corresponding equations

$$
\begin{gathered}
\sigma=\sigma_{m} \cdot\left(1-\frac{t}{\theta}\right), \text { when } 0 \leq t \leq \theta \\
\sigma=0, \text { when } 0 \geq t, t \geq \theta
\end{gathered}
$$

where $\sigma_{m}$ is the maximum stress in the contact spot of the propeller with the soil, $\mathrm{Pa}$; $\theta$ is the half-period of oscillations, $\mathrm{s}^{-1}$. Solving the equation (1), we obtain a change in the relative deformation of the soil from the acting shock (dynamic) loads of propulsion.
$\varepsilon(t)=-\frac{D_{0}}{\mu}-\frac{B_{0}}{\mu^{2}} \cdot(\mu t-1)+C_{0} \cdot e^{-\mu \cdot t}$,

where $\quad B_{0}=\frac{\mu \cdot \sigma_{m}}{E_{C} \cdot \theta}, s^{-2} ; \quad D_{0}=\frac{\sigma_{m}}{E_{D} \cdot \theta} \cdot\left(1-\frac{E_{D}}{E_{C}} \cdot \mu \cdot \theta\right), s^{-1}$; $C_{0}=\frac{\sigma_{m}}{E_{D}}+\frac{D_{0}}{\mu}-\frac{B_{0}}{\mu^{2}}$ are coefficients taking into account the soil properties and the magnitude of mechanical stresses.

When driving a tractor on periodically repeated irregularities, the stress in the soil varies according to the formulas

$$
\begin{gathered}
\sigma=0 \text { when } t \leq 0 \\
\sigma=\sigma_{m} \cdot \sin \lambda t=\sigma_{m} \cdot \frac{\sin 2 \pi t}{T} \text { when } 0 \leq t \leq \infty
\end{gathered}
$$

where $\lambda$ is the frequency of angular forced oscillations, $\mathrm{s}^{-1}$;

$\lambda=\frac{2 \pi}{T}$

$T$ is the period of forced oscillations, s;

$T=\frac{L}{V}$,

where $L$ is the length of irregularities of the support surface, m;

$V$ is the tractor speed, $\mathrm{m} / \mathrm{s}$.

Solving equations (2), we obtain a change in the relative deformation of the soil caused by the operating sinusoidal loads of propulsion

$$
\begin{aligned}
& \varepsilon(t)=\frac{K}{\lambda^{2}+\mu^{2}} \cdot(\lambda \cdot \sin \lambda t+\mu \cdot \cos \lambda t)+ \\
& +\frac{L}{\lambda^{2}+\mu^{2}} \cdot(\mu \cdot \sin \lambda t-\lambda \cos \lambda t)+C \cdot e^{-\mu t},
\end{aligned}
$$

where $\quad K=\frac{\sigma_{m} \lambda}{E_{D}}, s^{-1} ; L=\frac{\mu \sigma_{m}}{E_{C}}, s^{-1} ; C=\frac{\sigma_{m}}{E_{D}}+\frac{L \cdot \lambda-K \cdot \mu}{\lambda^{2}+\mu^{2}}$ are the coefficients taking into account the soil properties and the mechanical stress acting on it.

The rolling of a wheel propeller is presented in the form of a twomass equivalent vibrational system (in the case of a suspension bracket, the front axle, Fig. 1) moving along the support surface given by the equation.

$y=y_{\max } \cdot \sin \lambda t$,

where $y_{\max }$ is the maximum height of the surface roughness, $\mathrm{m}$. After calculating the value of the relative soil deformation, it is possible to determine the change in soil density after the impact of wheel propulsion on it according to the dependence known from the mechanics of soils [6]

$\rho_{a}=\frac{\rho_{b}}{1-\varepsilon}$,

where $\rho_{b}, \rho_{a}$ is the soil density before an impact (initial) and after an impact, $\mathrm{g} / \mathrm{cm}^{3} ; \varepsilon$ is the relative deformation of soil.

To determine vertical movements of the tractor body, let's construct the equations of projection of forces on the vertical $Z$ axis [6] 


$$
\begin{aligned}
\sum F_{Z} & =F_{\mathrm{spr}}-F_{\mathrm{abs} 1}+F_{\mathrm{tir} 2}-F_{\mathrm{abs} \operatorname{tir} 2}-N_{\mathrm{cl}} \cdot \cos \varphi- \\
& -F_{\mathrm{in}}-G+P_{\mathrm{dr}} \cdot \sin \varphi-m_{2} \cdot g=0,
\end{aligned}
$$

where $G$ is the force of gravity, $\mathrm{N} ; F_{i n}$ is the force of inertia of the tractor body, $\mathrm{N} ; F_{s p r}$ is the force of the elastic element of the suspension (springs) of the front axle, $\mathrm{N} ; F_{a b s l}$ is the force created by the shock absorber of the front axle suspension, $\mathrm{N} ; F_{t i r 2}$ is the force created by the elasticity of the rear axle tire, $\mathrm{N} ; F_{a b s}$ tir 2 is the force that takes into account the damping properties of the rear axle tire, $\mathrm{N} ; N_{c l}$ is the vertical component of traction force, $\mathrm{N}$;

$P_{d r}$ is the horizontal component of traction force, $\mathrm{N} ; m_{2}$ is the mass of the rear tractor axle, $\mathrm{kg} ; g$ is the acceleration of free fall, $\mathrm{m} / \mathrm{s}^{2}$.

The strength of the elastic element of the front suspension of the tractor

$$
\begin{aligned}
& F_{p}=C_{\mathrm{p}} \cdot\left(f_{\mathrm{st} 1}-\mathrm{z}+a \cdot \varphi+\xi_{1}\right) \\
& f_{\mathrm{st} 1}=\frac{b \cdot G}{a+b} \cdot \frac{1}{C_{\mathrm{p}}}=\frac{G \cdot b}{C_{\mathrm{p}} \cdot(a+b)} ; \\
& F_{\mathrm{p}}=G \cdot \frac{b}{a+b}-C_{\mathrm{p}} \cdot z+C_{\mathrm{p}} \cdot a \cdot \varphi+C_{\mathrm{p}} \cdot \xi_{1},
\end{aligned}
$$

where $f_{\mathrm{st} 1}$ is the static deformation of the springs of the front suspension, $\mathrm{m}$.

The force created by the shock absorber of the front suspension is determined by the formula

$$
F_{\mathrm{abs} 1}=k_{\mathrm{p}} \cdot\left(\dot{z}-\dot{\xi}_{1}-a \cdot \dot{\varphi}\right)=k_{\mathrm{p}} \cdot \dot{z}-k_{\mathrm{p}} \cdot \dot{\xi}_{1}-k_{\mathrm{p}} \cdot a \cdot \dot{\varphi} .
$$

The force generated by the tire elasticity is determined by the formula

$$
F_{\text {tir } 2}=C_{\text {tir } 2} \cdot\left(f_{\text {st.tir } 2}-z-b \cdot \varphi+y_{2}\right),
$$

where $y_{2}-$ is the profile of irregularities under the rear wheels, m.

The profile of irregularities under the rear wheels, taking into account the deformation of the soil $\varepsilon_{2}$ and the retardation of the effect $\tau$, is represented by the following dependence

$$
y_{2}(t)=y(t-\tau) \cdot\left(1-\varepsilon_{1} \cdot(t-\tau) \cdot\left(1-\varepsilon_{2}(t)\right)\right),
$$

where $\tau=\frac{2 \pi \cdot L_{\mathrm{tr}}}{\omega \cdot l_{\mathrm{av}}}$ is the delay of the perturbation under the rear wheels of the tractor, $\mathrm{s} ; \omega=\frac{2 \pi \cdot V_{\mathrm{tr}}}{l_{\mathrm{av}}}$ is the perturbation frequency, $\mathrm{s}^{-1}$.

Let's determine the stress in the contact spot of the rear wheel with the soil $\sigma_{2}$ by the following dependence

$$
\sigma_{2}=\frac{1}{\mathrm{~F}_{\mathrm{k}} \cdot\left(y_{2}\left(t, \varepsilon_{1}, \varepsilon_{2}\right)-z-b \cdot \phi\right)} \cdot\left(F_{\text {tir } 2}-F_{\text {abs tir2 } 2}\right),
$$

where $\mathrm{F}_{\mathrm{k}}=\frac{\pi}{4} \cdot a_{\mathrm{k}} \cdot b_{\mathrm{k}}$ is the contour area of the contact spot of the wheel with the soil, $\mathrm{m}^{2} ; a_{\mathrm{k}}, b_{\mathrm{k}}$ is the length and width of the contact area, $\mathrm{m}$.

Forces from the suspension - shock absorbers and springs, as well as the force of gravity, the force of inertia and the moment of inertia of the mobile machine (Fig. 2) act on the tractor body.

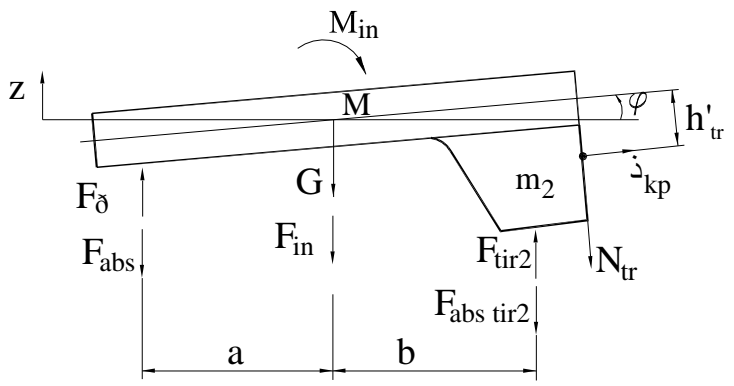

Fig. 2: Forces acting on the spring tractor mass

The static deformation of the rear tires is determined by the formula

$f_{\text {st.tir } 2}=\frac{G \frac{a}{a+b}+m_{2} \cdot g}{C_{\text {tir } 2}}$.

Then

$F_{\text {tir } 2}=\mathrm{G} \frac{\mathrm{a}}{\mathrm{a}+\mathrm{b}}+m_{2} \cdot g-C_{\text {tir } 2} \cdot \mathrm{z}-C_{\text {tir } 2} \cdot b \cdot \varphi+C_{\text {tir } 2} \cdot y_{2}$

The force that takes into account the tire damping properties

$F_{\text {abs tir2 }}=k_{\text {tir } 2}\left(\dot{z}-\dot{y}_{2}+b \dot{\varphi}\right)=k_{\text {tir } 2} \dot{z}-k_{\text {tir } 2} \dot{y}_{2}+k_{\text {tir } 2} b \dot{\varphi}$,

where $\dot{y}_{2}$ is the rate of change in the height of the road profile under the rear wheels, $\mathrm{m} / \mathrm{s}$.

Spring-suspended weight

$G=M \cdot g$,

where $g$ is the acceleration of free fall, $g=9,81 \mathrm{~m} / \mathrm{s}^{2} ; M$ is the mass of the tractor body, $\mathrm{kg}$.

$F_{\text {in }}=\left(M+m_{2}\right) \cdot \ddot{z}$,

where $\ddot{z}$ is the acceleration of the tractor body movement in the vertical direction; $m_{2}$ is the mass of the rear tractor axle.

From the equation (9) obtained we express the value of the dynamic load applied to the rear axle wheels

$G_{k 2}=F_{a b s 1}+F_{a b s t i r 2}+m_{2} \ddot{\xi}_{2}+N_{\mathrm{tr}} \cos \varphi-P_{k p} \sin \varphi-F_{p}$.

Substituting the equations (10) - (21) in (9) we obtain

$$
\begin{aligned}
& G \cdot \frac{b}{a+b}-C_{\mathrm{p}} \cdot z+C_{\mathrm{p}} \cdot a \cdot \varphi+C_{\mathrm{p}} \cdot \xi_{1}-k_{\mathrm{p}} \cdot \dot{z}+k_{\mathrm{p}} \cdot \dot{\xi}_{1}+ \\
& +k_{\mathrm{p}} \cdot a \cdot \dot{\varphi}+G \cdot \frac{a}{a+b}+m_{2} \cdot g-C_{\mathrm{tir} 2} \cdot \mathrm{z}-C_{\mathrm{tir} 2} \cdot b \cdot \varphi+ \\
& +C_{\mathrm{tir} 2} \cdot y_{2}-k_{\mathrm{tir} 2} \cdot \dot{\mathrm{z}}+k_{\mathrm{tir} 2} \cdot \dot{y}_{2}-k_{\mathrm{tir} 2} \cdot \mathrm{b} \cdot \dot{\varphi}-N_{\mathrm{tr}} \cdot \cos \varphi- \\
& \quad-\left(M+m_{2}\right) \cdot \ddot{z}-G+P_{\mathrm{kp}} \cdot \sin \varphi-m_{2} \cdot g=0 ; \\
& -\left(M+m_{2}\right) \cdot \ddot{\mathrm{z}}-\left(k_{\mathrm{p}}+k_{\mathrm{tir} 2}\right) \cdot \dot{z}-\left(C_{\mathrm{p}}+C_{\mathrm{tir} 2}\right) \cdot \mathrm{z}+ \\
& +\left(k_{\mathrm{p}} \cdot a-k_{\mathrm{tir} 2} \cdot \mathrm{b}\right) \cdot \dot{\varphi}+\left(C_{\mathrm{p}} \cdot a-C_{\mathrm{tir} 2} \cdot b\right) \cdot \varphi- \\
& -N_{\mathrm{tr}} \cdot \cos \varphi+P_{\mathrm{tp}} \cdot \sin \varphi+k_{\mathrm{p}} \cdot \dot{\xi}_{1}+C_{\mathrm{p}} \cdot \xi_{1}= \\
& \quad=-k_{\mathrm{tir} 2} \cdot \dot{y}_{2}-C_{\mathrm{tir} 2} \cdot y_{2} .
\end{aligned}
$$

Let's divide the resulting equation by $-\left(M+m_{2}\right)$ then 


$$
\begin{aligned}
& \ddot{z}+\frac{k_{\mathrm{p}}+k_{\text {tir } 2}}{\mathrm{M}+\mathrm{m}_{2}} \dot{z}+\frac{C_{\mathrm{p}}+C_{\mathrm{tir} 2}}{\mathrm{M}+\mathrm{m}_{2}} \cdot z-\frac{k_{\mathrm{p}} \cdot a-k_{\text {tir } 2} \cdot \mathrm{b}}{\mathrm{M}+\mathrm{m}_{2}} \cdot \dot{\varphi}- \\
& -\frac{C_{\mathrm{p}} \cdot a-C_{\text {tir } 2} \cdot \mathrm{b}}{\mathrm{M}+\mathrm{m}_{2}} \cdot \varphi-\frac{N_{\mathrm{tr}} \cdot \cos \varphi}{\mathrm{M}+\mathrm{m}_{2}}+\frac{P_{\mathrm{kp}} \cdot \sin \varphi}{\mathrm{M}+\mathrm{m}_{2}}- \\
& -\frac{k_{\mathrm{p}}}{\mathrm{M}+\mathrm{m}_{2}} \dot{\xi}_{1}-\frac{C_{\mathrm{p}}}{\mathrm{M}+\mathrm{m}_{2}} \xi_{1}=\frac{k_{\mathrm{tir} 2}}{\mathrm{M}+\mathrm{m}_{2}} \dot{y}_{2}+\frac{C_{\mathrm{tir} 2}}{\mathrm{M}+\mathrm{m}_{2}} y_{2} .
\end{aligned}
$$

To determine the angular displacement of the tractor body, we make the equation of the sum of moments relative to the center of mass

$$
\begin{aligned}
& \begin{array}{l}
\sum M_{\mathrm{c} . \mathrm{m}}=F_{\mathrm{abs} 1} \cdot a-F_{\mathrm{p}} \cdot a+F_{\mathrm{tir} 2} \cdot b-F_{\mathrm{abstir} 2} \cdot b- \\
\quad-N_{\mathrm{tr}} \cdot\left(b+l_{\mathrm{kp}}\right)+P_{\mathrm{kp}} \cdot h_{\mathrm{tr}}^{\prime}-M_{\mathrm{in}}=0
\end{array} \\
& \left|M_{\mathrm{in}}\right|=J \cdot \ddot{\varphi} \\
& \left|M_{\mathrm{in}}\right|=\left(J+J_{2}\right) \cdot \ddot{\varphi},
\end{aligned}
$$

where $M_{\text {in }}$ is the moment of forces of inertia of the spring weight relative to the center of mass; $J$ is the moment of inertia of the spring weight relative to the center of mass, $\mathrm{kg} \times \mathrm{m}^{2} ; J_{2}$ is the moment of inertia of the rear axle relative to the center of mass of the tractor body, $\mathrm{kg} \times \mathrm{m}^{2}$.

The moment of inertia of the tractor body is determined by the formula

$$
J=M \cdot \rho_{i n}{ }^{2}
$$

where $M$ is the spring weight of the tractor, $\mathrm{kg}$;

$\rho_{\mathrm{in}}$ is the radius of inertia of the tractor body, $\mathrm{kg} \times \mathrm{m}^{2}$;

$$
J_{2}=m_{2} \cdot b^{2} \text {. }
$$

Substituting the equations (13) - (20) and (17) - (30) into equation (26), we obtain

$$
\begin{aligned}
& k_{\mathrm{p}} \cdot a \cdot \dot{z}-k_{\mathrm{p}} \cdot a \cdot \dot{\xi}_{1}-k_{\mathrm{p}} \cdot a^{2} \cdot \dot{\varphi}-G \cdot \frac{b \cdot a}{a+b}+C_{\mathrm{p}} \cdot a \cdot z- \\
& -C_{\mathrm{p}} \cdot a^{2} \cdot \varphi-C_{\mathrm{p}} \cdot a \cdot \xi_{1}+G \cdot \frac{a \cdot b}{a+b}-m_{2} \cdot g \cdot b-C_{\mathrm{tir} 2} \cdot b \cdot z- \\
& -C_{\mathrm{tir} 2} \cdot b^{2} \cdot \varphi+C_{\mathrm{tir} 2} \cdot b \cdot y_{2}-k_{\mathrm{tir} 2} \cdot b \cdot \dot{\mathrm{z}}+k_{\mathrm{tir} 2} \cdot b \cdot \dot{y}_{2}- \\
& -k_{\mathrm{tir} 2} \cdot b^{2} \cdot \dot{\varphi}-N_{\mathrm{tr}} \cdot\left(b+l_{\mathrm{kp}}\right)+P_{\mathrm{kp}} \cdot h_{\mathrm{tr}}^{\prime}-\left(J+J_{2}\right) \cdot \ddot{\varphi}=0 \\
& -\left(J+J_{2}\right) \ddot{\varphi}-\left(k_{\mathrm{p}} a^{2}+k_{\mathrm{tir} 2} b^{2}\right) \dot{\varphi}-\left(C_{\mathrm{p}} a^{2}+C_{\mathrm{tir} 2} b^{2}\right) \varphi+ \\
& +\left(k_{\mathrm{p}} a-k_{\mathrm{tir} 2} b\right) \dot{z}+\left(C_{\mathrm{p}} a-C_{\mathrm{tir} 2} b\right) z-k_{\mathrm{p}} a \dot{\xi}_{1}-C_{\mathrm{p}} a \xi_{1}= \\
& =-k_{\mathrm{tir} 2} b \dot{y}_{2}-C_{\mathrm{tir} 2} b y_{2}+N_{\mathrm{tr}}\left(b+l_{\mathrm{kp}}\right)+m_{2} g b-P_{\mathrm{kp}} h_{\mathrm{tr}}^{\prime} \cdot
\end{aligned}
$$

Let's divide the resulting equation by $-\left(J+J_{2}\right)$ then

$$
\begin{aligned}
& \ddot{\varphi}+\frac{k_{\mathrm{p}} \cdot a^{2}+k_{\mathrm{tir} 2} \cdot \mathrm{b}^{2}}{J+J_{2}} \cdot \dot{\varphi}+\frac{C_{\mathrm{p}} \cdot a^{2}+C_{\mathrm{tir} 2} \cdot \mathrm{b}^{2}}{J+J_{2}} \cdot \varphi- \\
& -\frac{k_{\mathrm{p}} \cdot a-k_{\mathrm{tir} 2} \cdot \mathrm{b}}{J+J_{2}} \cdot \dot{z}-\frac{C_{\mathrm{p}} \cdot a-C_{\mathrm{tir} 2} \cdot \mathrm{b}}{J+J_{2}} \cdot z+\frac{k_{\mathrm{p}} \cdot a}{J+J_{2}} \cdot \dot{\xi}_{1}+ \\
& +\frac{C_{\mathrm{p}} \cdot a}{J+J_{2}} \cdot \xi_{1}=\frac{k_{\mathrm{tir} 2} \cdot \mathrm{b}}{J+J_{2}} \cdot \dot{y}_{2}+\frac{C_{\mathrm{tir} 2} \cdot \mathrm{b}}{J+J_{2}} \cdot y_{2}+ \\
& +\frac{N_{\mathrm{tr}} \cdot\left(b+l_{\mathrm{kp}}\right)}{J+J_{2}}+\frac{m_{2} \cdot g \cdot b}{J+J_{2}}-\frac{P_{\mathrm{kp}} \cdot h_{\mathrm{tr}}^{\prime}}{J+J_{2}} .
\end{aligned}
$$

Various forces act on the unsprung mass of the tractor, that is the front axle $\xi_{1}$, the scheme of application of which is presented in Fig. 3

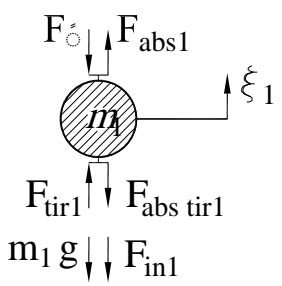

Fig. 3: Forces acting on the front axle of the tractor

Let's apply the external forces, the reactions of bonds and the forces of inertia (Fig. 3) to the unsteady mass and write the sum of projections of forces on the vertical axis.

The sum of projections of forces acting on the front axle of the tractor

$\sum F_{\xi_{1}}=0$

or

$F_{\text {abs1 }}-F_{\mathrm{p}}+F_{\text {tir } 1}-F_{\text {abs tir } 1}-m_{1} g-F_{\text {in } 1}=0$,

where $F_{\text {tir } I}$ is the force generated by the tire elasticity;

$F_{a b s \text { tir } 1}$ is the force that takes into account the tire damping properties;

$F_{\text {tir1 }}=C_{\text {tir } 1} \cdot\left(f_{\text {st tir1 }}-\xi_{1}+y_{1}\right)$,

where $y_{1}$ is the height of the profile of the road under the front wheels, m;

The height of the profile of the road under the front wheels, taking into account the deformation of the soil $\varepsilon_{1}$ is determined by the following dependence

$y_{1}=y(t) \cdot\left(1-\varepsilon_{1}(t)\right)$

where $\varepsilon_{1}$ is the deformation of soil caused by passing of front wheels, $\mathrm{m}$.

$$
\begin{aligned}
& f_{\text {st tir } 1}=\frac{G \frac{b}{a+b}+m_{1} \cdot g}{C_{\text {tir } 1}} ; \\
& F_{\text {tir } 1}=G \frac{b}{a+b}+m_{1} \cdot g-C_{\text {tir } 1} \cdot \xi_{1}+C_{\text {tir } 1} \cdot y_{1} ; \\
& F_{\text {abs tir } 1}=k_{\text {tir } 1}\left(\dot{\xi}_{1}-\dot{y}_{1}\right)=k_{\text {tir } 1} \cdot \dot{\xi}_{1}-k_{\text {tir } 1} \cdot \dot{y}_{1},
\end{aligned}
$$

where $\dot{y}_{1}$ is the rate of change in the height of the profile of the road under the front wheels, $\mathrm{m} / \mathrm{s}$;

$\left|F_{\text {in } 1}\right|=m_{1} \cdot \ddot{\xi}_{1}$

From the equation (34) obtained we express the value of the dynamic load applied to the front axle wheels

$G_{k 1}=F_{\mathrm{p}}+F_{\mathrm{abs} \text { tir } 1}-F_{\mathrm{absl}}+m_{1} \cdot \ddot{\xi}_{1}$

Substituting equations (35) - (40) into equation (34), we obtain

$$
\begin{aligned}
& k_{\mathrm{p}} \cdot \dot{\mathrm{z}}-k_{\mathrm{p}} \cdot \dot{\xi}_{1}-k_{\mathrm{p}} \cdot a \cdot \dot{\varphi}-G \cdot \frac{b}{a+b}+C_{\mathrm{p}} \cdot z-C_{\mathrm{p}} \cdot a \cdot \varphi- \\
& -C_{\mathrm{p}} \cdot \xi_{1}+G \cdot \frac{b}{a+b}+m_{1} \cdot g-C_{t i r 1} \cdot \xi_{1}+C_{t i r 1} \cdot y_{1}- \\
& \quad-k_{t i r 1} \cdot \dot{\xi}_{1}+k_{t i r 1} \cdot \dot{y}_{1}-m_{1} \cdot g-m_{1} \cdot \ddot{\xi}_{1}=0 ;
\end{aligned}
$$


$-m_{1} \cdot \ddot{\xi}_{1}-\left(k_{\mathrm{p}}+k_{\text {tir } 1}\right) \cdot \dot{\xi}_{1}-\left(C_{\mathrm{p}}+C_{\text {tir } 1}\right) \cdot \xi_{1}+k_{\mathrm{p}} \cdot \dot{z}+$

$+C_{\mathrm{p}} \cdot z-k_{\mathrm{p}} \cdot a \cdot \dot{\varphi}-C_{\mathrm{p}} \cdot a \cdot \varphi=-k_{\text {tir } 1} \cdot \dot{y}_{1}-C_{\text {tir } 1} \cdot y_{1}$.

Let's divide the resulting equation into $-m_{1}$ and then

$$
\begin{gathered}
\ddot{\xi}_{1}+\frac{k_{\mathrm{p}}+k_{t i r 1}}{\mathrm{~m}_{1}} \cdot \dot{\xi}_{1}+\frac{C_{\mathrm{p}}+C_{t i r 1}}{\mathrm{~m}_{1}} \cdot \xi_{1}-\frac{k_{\mathrm{p}}}{\mathrm{m}_{1}} \cdot \dot{z}-\frac{C_{p}}{\mathrm{~m}_{1}} \cdot z+ \\
+\frac{k_{\mathrm{p}} \cdot a}{\mathrm{~m}_{1}} \cdot \dot{\varphi}+\frac{C_{\mathrm{p}} \cdot a}{\mathrm{~m}_{1}} \cdot \varphi=\frac{k_{t i r 1}}{\mathrm{~m}_{1}} \cdot \dot{y}_{1}+\frac{C_{t i r 1}}{\mathrm{~m}_{1}} \cdot y_{1} \cdot
\end{gathered}
$$

To simulate the deformation of the support surface, that is the soil, we adopt a model that takes into account both the elastic and viscous properties. The general view of the soil model is presented in Fig. 4.

Let's compile equations for the upper and lower parts of the model

$$
E_{D} \cdot x-E_{D} \cdot \varepsilon-\sigma=0
$$

where $E_{D}$ is the dynamic soil elasticity modulus, $\mathrm{Pa} ; \sigma$ is the mechanical stress that acts on the soil, $\mathrm{Pa} ; \varepsilon$ is the relative deformation of soil.
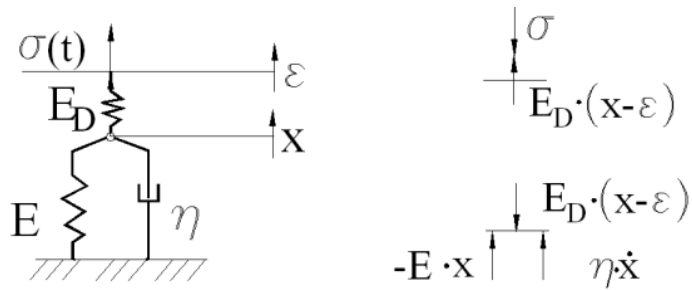

Fig. 4: General view of the soil model

The equation of connection has the following form

$$
-E \cdot x-E_{D} \cdot(x-\varepsilon)-\eta \cdot \dot{x}=0,
$$

where $E$ is the modulus of elasticity, $\mathrm{Pa}$; $\eta$ is the coefficient of viscosity, $\mathrm{Pa} \cdot \mathrm{s}$.

We express from equation (44)

$$
\begin{aligned}
& x=\varepsilon+\frac{\sigma}{E_{D}} ; \\
& \dot{x}=\dot{\varepsilon}+\frac{\dot{\sigma}}{E_{D}} .
\end{aligned}
$$

Substituting the resulting equation into equation (45) we obtain

$$
\begin{aligned}
& -E \cdot\left(\varepsilon+\frac{\sigma}{E_{D}}\right)-E_{D} \cdot\left(\varepsilon+\frac{\sigma}{E_{D}}-\varepsilon\right)-\eta \cdot\left(\dot{\varepsilon}+\frac{\dot{\sigma}}{E_{D}}\right)=0 \\
& -E \cdot \varepsilon-E \cdot \frac{\sigma}{E_{D}}-\sigma-\eta \cdot \dot{\varepsilon}-\eta \cdot \frac{\dot{\sigma}}{E_{D}}=0 \\
& -\eta \cdot \dot{\varepsilon}-E \cdot \varepsilon=\eta \cdot \frac{\dot{\sigma}}{E_{D}}+\sigma+E \cdot \frac{\sigma}{E_{D}} \\
& \dot{\varepsilon}+\frac{E}{\eta} \cdot \varepsilon=\eta \cdot \frac{1}{E_{D}} \cdot \dot{\sigma}+\frac{1+\frac{E}{E_{D}}}{\eta} \cdot \sigma .
\end{aligned}
$$

The maximum mechanical stress in the contact spot of the front and rear axle wheels with the soil is calculated according to the formula

$$
\begin{aligned}
& \sigma_{m 1}=\frac{G_{k 1}}{F_{k 1}} ; \dot{\sigma}_{m 1}=\frac{\dot{G}_{k 1}}{F_{k 1}} ; \\
& \sigma_{m 2}=\frac{G_{k 2}}{F_{k 2}} ; \dot{\sigma}_{m 2}=\frac{\dot{G}_{k 2}}{F_{k 2}} .
\end{aligned}
$$

Then the connection between the deformation of the soil and the mechanical stress caused by the wheel, taking into account the properties of the soil, appears to be a dependence

$$
\left\{\begin{array}{l}
\dot{\varepsilon}_{1}+\mu_{1} \cdot \varepsilon_{1}=\frac{\dot{\sigma}_{1}}{E_{D 1}}+\frac{\mu_{1} \cdot \sigma_{1}}{E_{C 1}}, \\
\dot{\varepsilon}_{2}+\mu_{2} \cdot \varepsilon_{2}=\frac{\dot{\sigma}_{2}}{E_{D 2}}+\frac{\mu_{2} \cdot \sigma_{2}}{E_{C 2}} .
\end{array}\right.
$$

During the operation of the machine-tractor unit on the field at different areas of the contact spot of the tire, the soil is compacted with the formation of a track of varying depth (Fig. 5).

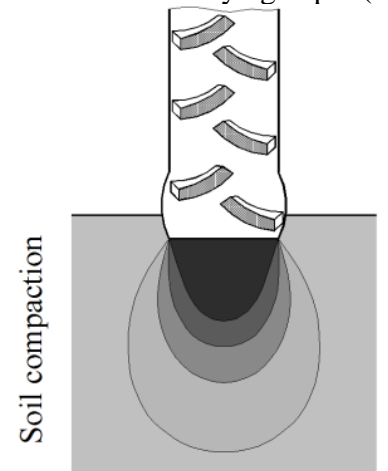

Fig. 5: Soil compaction caused by a tractor

The solution of most tasks on the choice of optimal parameters and operating modes of mobile machines and tractors is based on experimental data.

Experimental studies of the dynamic properties of mobile machines (Fig. 6) are based on measuring the driving parameters by various inertial sensing elements and systems in real driving conditions. The method of partial acceleration proposed by the authors of the paper [15] allows determining the dynamic indices of mobile agricultural machines and aggregates using threecomponent linear acceleration sensors. But in this case, the tests must be carried out on a particular agricultural background with a hinge of a particular agricultural tool.

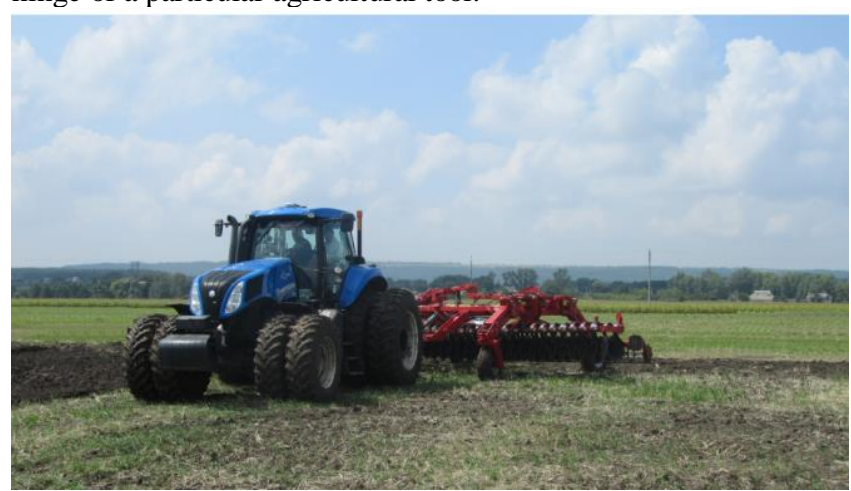

Fig. 6: Mobile agricultural machine (New Holland T8.390 + DLM-8.0)

With straightforward motion, all the points of the mobile machines have the same kinematic parameters. When conducting dynamic tests, parameter control is carried out using a measuring and recording complex equipped with three-component accelerometer 
sensors (Fig. 7). In order to ensure a qualitative process for controlling the dynamics of the unit, it is necessary to install such a number of sensors, which will allow controlling all directions of the axes of degrees of the mobile aggregate freedom.

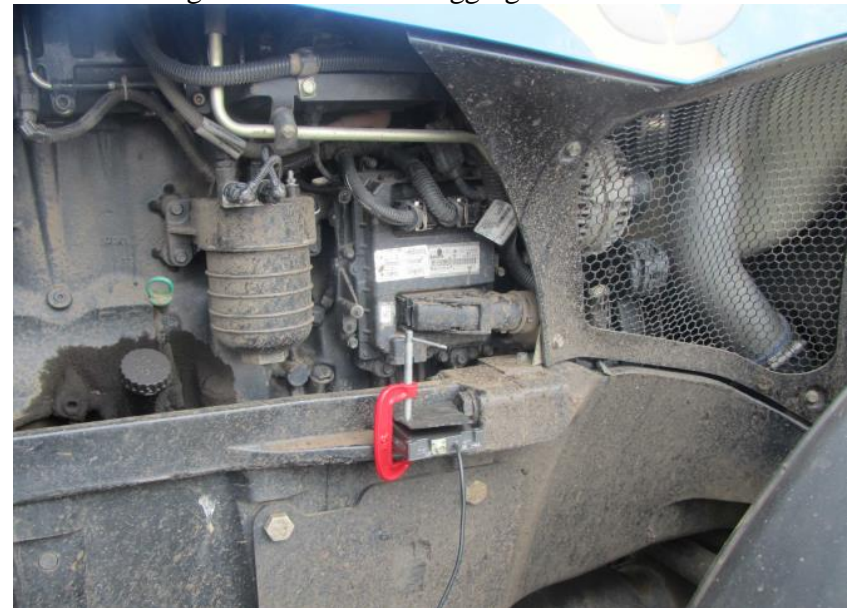

Fig. 7: Installation the sensors (MMA-7260QT) of measuring and recording complex on mobile agricultural machine New Holland T8.390

In the process of conducting experimental tractor driving studies, changes in vertical accelerations were recorded, using a mobile measuring system.

To ensure the required accuracy of measurements, it is necessary to minimize the errors of the transient and steady-state operating modes of the MTA. When choosing a filtration algorithm, the following conditions must be followed: speed of convergence, adaptability, stability, requirements to computing resources. Thus, in order to improve the quality of the signal coming from accelerometers in dynamic testing of mobile machines, it is necessary to use or construct an adaptive filter.

Since the Butterworth's first-order filters have good characteristics, many researchers use them in their work. In practice, filters with order $n=2 \ldots 8$ we usually used. Let's filter the signal, Fig. 8.

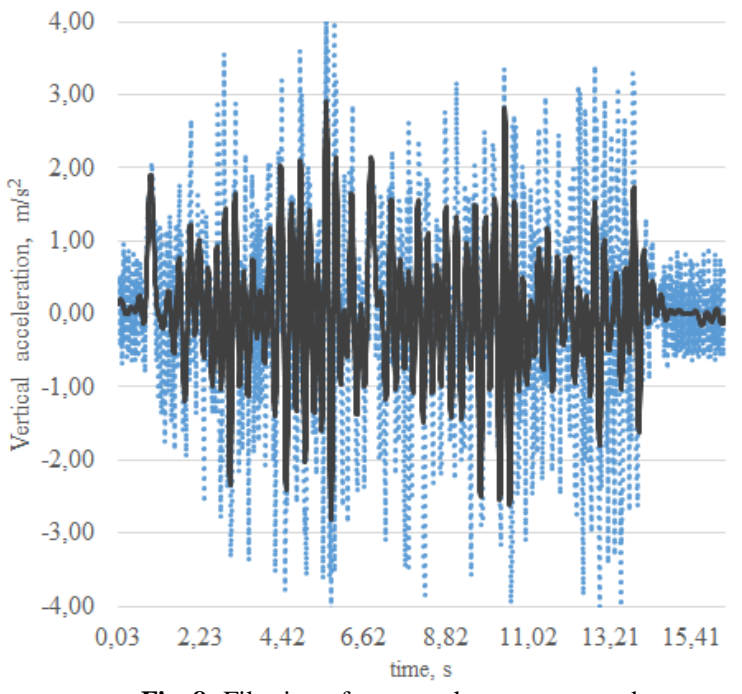

Fig. 8: Filtering of raw accelerometer records

After filtration of the signal, we can determine the forces acting on the body and the tractor undercarriage system.

\section{Conclusions}

Based on the research carried out, the modeling of the effect of dynamic loads and vertical accelerations of the wheeled tractor on the change in soil density is based on the following conclusions:

- The influence of parameters and characteristics of the running gear system of the wheeled tractor, as well as the traction load on the value of vertical accelerations when moving along the soil, is determined;
- The dependence of the influence of vertical accelerations on the dynamic loads on the axle of the tractor front and rear axles is determined;

- The dependence of the soil density variation caused by the action of dynamic loads from the propulsion of the tractor front and rear axles has been determined.

\section{Acknowledgement}

The authors are thankful to Kharkiv National Automobile and Highway University (Kharkiv, Ukraine), Kharkiv Petro Vasylenko National Technical University of Agriculture (Kharkiv, Ukraine), National Technical University "Kharkiv Polytechnic Institute" (Kharkiv, Ukraine) and National Aerospace University "Kharkiv Aviation Institute" (Kharkiv, Ukraine) scientists for their cooperation in completing this study.

\section{References}

[1] Shahgholi Gh, Chiyaneh HG, Gundoshmian TM, "Modeling of Soil Compaction Beneath the Tractor Tire using Multilayer Perceptron Neural Networks", Journal of Agricultural Machinery, Vol.8, No.1, (2018), pp. 105-118.

[2] Artemenko D, Onopa V \& Skrynnick S, "Construction substantiation of the combined packer wheel of the seed drill", ScienceRise, Vol.11, (2016), pp. 25-29.

[3] Filipović D, Husnjak S, Košutić S, Gospodarić Z, Kovačev I \& Čopec K, "Impact of the repeated tractor passes on some physical properties of silty loam soil", Poljoprivreda, Vol.17, No.2, (2011), pp. 43-48.

[4] Albiero D, Jose da Silva MA \& Maria Dal FI, "Load distribution on soil profile as generated by farm machinery tires", Revista Brasileira de Engenharia de Biossistemas, Vol.2, No.2, (2008), pp. 129 142 .

[5] Weizheng L, Shuai Q, Zhihong N \& Junhui Z, "Effects of Density and Moisture Variation on Dynamic Deformation Properties of Compacted Lateritic Soil", Advances in Materials Science and Engineering, Vol.2016, (2016), 11.

[6] Shipilevskiy G, "Creation of the MTU unified mathematical model", Tractors and agricultural machinery, Vol.3, (2000), pp. 17-19.

[7] Zolotarevskaya D, Calculation of propulsors with soil interaction indicators, Tractors and agricultural machinery, Vol.3, (2001), pp. 18-22.

[8] Burlaka V, Tishchenko L, Shebanov O, Theoretical mechanics. Dynamics, Miskdruk, (2014), pp. 380.

[9] Caruana Martins PC, Dias Junior MS, Carvalho Andrade ML, Gontijo Guimarães PT, "Compaction caused by mechanized operations in a Red-Yellow Latosol cultivated with coffee over time", Ciência e Agrotecnologia, Vol.36, No.4, (2012), pp. 391-398.

[10] Soracco CG, Lozano LA, Villarreal R, Palancar TC, Collazo DJ, Sarli GO, Filgueira RR, "Effects of compaction due to machinery traffic on soil pore configuration", Revista Brasileira de Ciência do Solo, Vol.39, No.2, (2015), pp. 408-415.

[11] Marinello F, Pezzuolo A, Cillis D, Chiumenti A, Sartori L, "Traffic effects on soil compaction and sugar beet (Beta vulgaris L.) taproot quality parameters", Spanish Journal of Agricultural Research, Vol. 15, No. 1, (2017), pp. 201.

[12] Edem I, Udoinyang UC, Udounang PI, “Tractor Effects on Soil Properties and the Consequences on Cassava (Manihot esculenta Crantz) Yield in Ultisol", International Journal of Environment, Vol.4, No.1, (2015), pp. 210-223.

[13] Klets D, Krasnokutsky M, Hatsko V, Barun M. "Modeling of operation processes of a motor grader engine during work under unsteady load", Eastern-European Journal of Enterprise Technologies, Vol. 4, No.7 (88), (2017), pp. 45-50.

[14] Podrigalo M, Kaidalov R, Klets D, Podrigalo N, Makovetskyi A, Hatsko V, Abramov D, Tarasov Y, Lytovchenko D \& Litvinov A, "Synthesis of energy efficient acceleration control law of automobile", Eastern-European Journal Of Enterprise Technologies, Vol.1 No.7(91), (2018), pp. 62-70.

[15] Artiomov N, Lebedev A, Podrigalo M, The method of parallel tripping and its application in the dynamics of mobile machines, Miskdruk, (2012), pp. 220 